\title{
NARROW BAND RATIO VEGETATION INDICES AND ITS RELATIONSHIPS WITH RICE AGRONOMIC VARIABLES
}

\author{
Fumin Wang, Jingfeng Huang * \\ Institute of Agricultural Remote Sensing \& Information Application Huajiachi Campus, \\ Zhejiang University Hangzhou 310029, P. R. China \\ * Corresponding author, Address: College of Environmental and Resource Sciences, Zhejiang \\ University, Hangzhou 310029, Zhejiang Province, P. R. China, Tel: +86-571-86971830, \\ Fax: +86-571-86971831,Email: Email:hjf@zju.edu.cn
}

Abstract: The present study aims to determine spectral bands that are best suited for characterizing rice agronomic variables. The data for this study came from ground-level hyperspectral reflectance measurements of rice at different stage. Reflectance was measured in discrete narrow bands between 350 and $2500 \mathrm{~nm}$. Observed rice agronomic variables included leaf area index (LAI), wet biomass (WBM including aboveground wet biomass-AGWBM, leaf wet biomass-LWBM, stem wet biomass-SWBM), and dry biomass(DBM: including aboveground dry biomass-AGDBM, leaf dry biomass-LDBM, stem dry biomass.) Firstly, narrow band ratio vegetation index (NBRVI) involving all possible two bands combinations of discrete channels were tested. The second part of the paper describes a rigorous search procedure to identify the best NBRVI predictors of rice agronomic variables. Special narrow band lambda $(\lambda 1)$ versus lambda $(\lambda 2)$ plots of $\mathrm{R} 2$ values illustrates the most effective wavelength combinations ( $\lambda 1$ and $\lambda 2)$ and band-widths ( $\Delta \lambda 1$ and $\Delta \lambda 2)$ for predicting rice agronomic variables at different development stages. The best of the NBRVI models explained $58 \%$ to $83 \%$ variability rice agronomic variables at different development stage. A strong relationship with rice agronomic variables is located in red-edge, $700 \mathrm{~nm}$ to $750 \mathrm{~nm}$, the longer portion of red $(650 \mathrm{~nm}$ to $700 \mathrm{~nm})$, the shorter portion of green $(500 \mathrm{~nm}$ to $550 \mathrm{~nm})$, a particular portion of NIR $(800 \mathrm{~nm}$ to $850 \mathrm{~nm})$. They are followed by moisture-sensitive NIR(1150nm to $1200 \mathrm{~nm})$, and two portions of SWIR $(1600 \mathrm{~nm}$ to $1650 \mathrm{~nm})$.

Keywords: hyperspectral remote sensing, narrow band ratio vegetation indices, rice agronomic variables

Please use the following format when citing this chapter:

Wang, F. and Huang, J., 2009, in IFIP International Federation for Information Processing, Volume 295, Computer and Computing Technologies in Agriculture II, Volume 3, eds. D. Li, Z. Chunjiang, (Boston: Springer), pp. 2187-2196. 


\section{INTRODUCTION}

Recent literature has shown that the narrow bands may be crucial for providing additional information with significant improvements over broad bands in quantifying biophysical and biochemical variables of agricultural crop. These hyperspectral studies were conducted for rice yield (Shibayama and Akiyama, 1991), chlorophyll content of plants (Blackburn, 1998), coniferous forest LAI (Gong et al., 1995), pinyon pine canopy LAI (Elvidge and Chen, 1995), and photosynthesis and stomatal conductance in pine canopies (Carter, 1998). The indices discussed in this paper involve two bands. According to Lawrence and Ripple (1998) and Gong et al.(1995), the use of two-band vegetation indices unnecessarily constrains the regression analysis. They argue that if one requires knowledge of an ecological variable (e.g., above-ground biomass or LAI), the researchers must ultimately analyze the relationship between the spectral index used and the ecological variable through a regression analysis. As the crop conditions vary due to factors such as management conditions, soil characteristics, climatic conditions, and cultural practices, different band combinations can be used (Shibayama and Akiyama, 1991; Shibayama et al., 1993). In the same time, theoretical models concerning the indices have been developed to describe the reflectance from single leaves to complete canopies. Many investigations demonstrated that reflection of red, green, and near-infrared radiation contains considerable information about crop biomass owing to the contrast between soil and vegetation. Thenkabail et al(1999) describe a rigorous search procedure to identify the best narrow band NDVI predictors of crop biophysical variables.

During the past several years, estimates of biomass, ground cover and leaf area indices (LAI) as a function of spectral reflectance measurements have shown promising results (Leblon et al.,1991; Clevers,1989).However, paddy rice being grown in continuously flooded fields, is a special crop which deserves particular consideration, as the layer of water on the soil surface modifies the spectral reflectance of the soil-plant system (Patel et al.,1985).

Based on the above background, the main goal of this research is to evaluate the performance of NBRVI in characterizing rice agronomic variables. The final goal is to determine and recommend an optimal number of hyperspectral bands, their centers and widths, in the visible, NIR portion and short-wave infrared portion of the spectrum $(350-2,500 \mathrm{~nm})$ required to best study rice, thus reducing the redundancy in hyperspectral data. A rigorous and exhaustive approach is adopted in computing and evaluating narrow band ratio vegetation index. Rice variables used are leaf area index (LAI), wet biomass (WBM: including aboveground wet biomass-AGWBM, leaf wet biomass -LWBM, stem wet biomass-SWBM, and root wet biomass-RWBM), dry biomass (DBM: including aboveground dry 
biomass - AGDBM, leaf dry biomass -LDBM, stem dry biomass-SDBM, and root dry biomass-RDBM), which are the best indicators of rice growth and yield (Bartlett et al., 1988; Wiegand and Richardson, 1990; Shibayama et al., 1993; Thenkabail et al., 1995; Fassnacht et al., 1997).

\section{EXPERIMENT SITE}

The study area is at Zhejiang University Experiment Farm, Hanghou, Zhejiang province, China, located $30^{\circ} 14^{\prime} \mathrm{N}, 120^{\circ} 10^{\prime} \mathrm{E}$. The data were obtained from three nitrogen fertilizer levels and five species treatments of rice in 2002 growing seasons. Rice cv. 'Xiushui 110(S1),Xieyou 9308(S2), Jiayu 293(S3), Jiazao 312(s4) and Z00324(S5)' were selected for the investigation. Xieyou 9308, Jiayu 293, Jiazao 312 and Z00324 are indica rice, and Xiushui japomica rice. Xieyou 9308 is a hybrid rice, others common rice. The three nitrogen fertilizer treatments(N0,N1,N2) of rice are fertilized $0,140,240 \mathrm{~kg} / \mathrm{ha}$ pure nitrogen respectively. Each treatment has four repeats. A completely randomized design consisting of 60 plots of $4.81 \mathrm{~m} \times 4.68 \mathrm{~m}$ was used, and 12 plots for each variety. Each plot was planted in east-west. The experiment area is characterized by monsoon climate with a hot summer and a cool winter, marked seasonal variations in precipitation. The average annual rainfall is $1374.7 \mathrm{~mm}$ from 1961 to 1990 . The sandy loam paddy soil had the following properties: $\mathrm{pH} 5.7$, organic matter with $16.5 \mathrm{~g} / \mathrm{kg}$ and total $\mathrm{N}$ with $1.02 \mathrm{~g} / \mathrm{kg}$.

\section{METHODOLOGY}

Spectral and agronomic variables data were gathered during the growing season of rice from June to October. A spectroradiometer with a range from $350 \mathrm{~nm}$ to $2500 \mathrm{~nm}$, manufactured by Analytical Spectral DevicesTM (FieldSPEC, 2002), was used to gather spectral data of rice at different stages. Due to severe noise in the water absorption regions, only the data gathered in $350 \mathrm{~nm}$ through $1330 \mathrm{~nm}$ and in 1480 through $1780 \mathrm{~nm}$ and $1990 \mathrm{~nm}$ through $2400 \mathrm{~nm}$ were used. The spectroradiometer unit consisted of a main spectrometer, a personal computer, fiber optic cable, a pistol grip, and different field of view (FOV) cones. Inside the spectrometer instrument, light is projected from the fiber optics onto a holographic diffraction grating where wavelength components are separated and reflected for independent collection by the detector(s) (FieldSPEC, 2002).

Rice Spectra and agronomic variables were observed seven times totally at their distinctive growth stages. These growth phases were: tillering, 
elongation, booting, heading, flowering, milk ripe, ripe, and harvest. At each plot, 10 reflectance measurements were consistently taken, with a nadir view from a height of $1.0 \mathrm{~m}$ above canopy, using a $25^{\circ} \mathrm{FOV}$. This resulted viewing an area of $6,939 \mathrm{~cm} 2$ at the canopy level. Spectroradiometer data of rice were analyzed using Data Processing System (DPS) version 6.12 (Tang, and Feng, 2002)

At the field of rice, a representative area was chosen for all measurements. The same rice sample was taken for laboratory analysis. In the laboratory, rice samples were analyzed for leaf area, wet weight, and dry weight. Rice samples were weighed on a simple weighing machine. Leave areas measurements were also made for all the rice samples, and then LAI were acquired.

Narrow band ratio vegetation indices(NBRVI) were computed using 1690 spectral channels of percentage reflectance data from the spectroradiometer. The performance of these indices in establishing rice agronomic variables were then evaluated and compared with the well-known reference Landsat $\mathrm{TM}$ broadband indices.

$$
\mathrm{NBRVI}=\mathrm{R}_{\mathrm{i}} / \mathrm{R}_{\mathrm{j}}
$$

where $i, j=1, N$ is reflectance(percent) of narrow bands with $\mathrm{N}=$ narrow bands $=1690 \mathrm{R}=$ reflectance of narrow bands

\section{RESULTS AND DISCUSSION}

\subsection{Narrow band RVI relationships with rice agronomic variables}

As many literatures depicted, RVI can give good prediction to LAI and WBM. Compared with NDVI, RVI is a simple, practical index. The availability of hyperspectral data in $1690(\mathrm{~N})$ discrete narrow bands allowed the computation of $\mathrm{N} \times \mathrm{N}=2856100$ NBRVIs for any rice agronomic variable. Regression coefficients $\mathrm{R}^{2}$ between all possible two-band NBRVIs and rice agronomic variables were determined. Therefore, the matrixes were obtained. The results of this comprehensive analysis are illustrated in contour plots of $\mathrm{R}^{2}$ values for all the pairs of wavelength. We determined a contour interval of 0.05 for $\mathrm{R}^{2}$ values. Based on the criterion, contour plots were made for all the agronomic variables of rice (Fig. 1). Since the $\mathrm{R}^{2}$ values are not symmetrical, the whole diagonal was occupied to display the matrix. Then band centers and band widths that combine to form the best nine indices were determined for rice biophysical variables of each observation date. After the results for various rice variables were evaluated, a strong 
relationships were showed, which centered in red-edge portion $(700 \mathrm{~nm}$ to $750 \mathrm{~nm})$, the longer portion of red $(650 \mathrm{~nm}$ to $700 \mathrm{~nm})$, the shorter portion of green $(500 \mathrm{~nm}$ to $550 \mathrm{~nm})$, a particular portion of NIR $(800 \mathrm{~nm}$ to $850 \mathrm{~nm})$. They are followed by moisture-sensitive NIR, and two portions of SWIR $(1150 \mathrm{~nm}$ to $1200 \mathrm{~nm}, 1600 \mathrm{~nm}$ to $1650 \mathrm{~nm})$. For the precise $R^{2}$ values, visually scan through $1690(\mathrm{~N})$ by $1690(\mathrm{~N})$ matrix of $\mathrm{R}^{2}$ values. Identify the $\lambda 1$ and $\lambda 2$ band centers having highest $R^{2}$ value. This is the band center for the index, which has highest correlation. Observe the $\mathrm{R}^{2}$ values in the immediate vicinity of these band centers $(\lambda 1$ and $\lambda 2)$.Often the $\mathrm{R}^{2}$ values remain the same or nearly the same for a few narrow bands in immediate vicinity of $\lambda 1$ and $\lambda 2$. This range of similar or near-similar spectral response to rice variable will constitute the bandwidth. Using the method, nine best he band centers $(\lambda 1$ and $\lambda 2)$ and band widths ( $\Delta \lambda 1$ and $\Delta \lambda 2)$ determined, only part of them are presented here (Table 1).

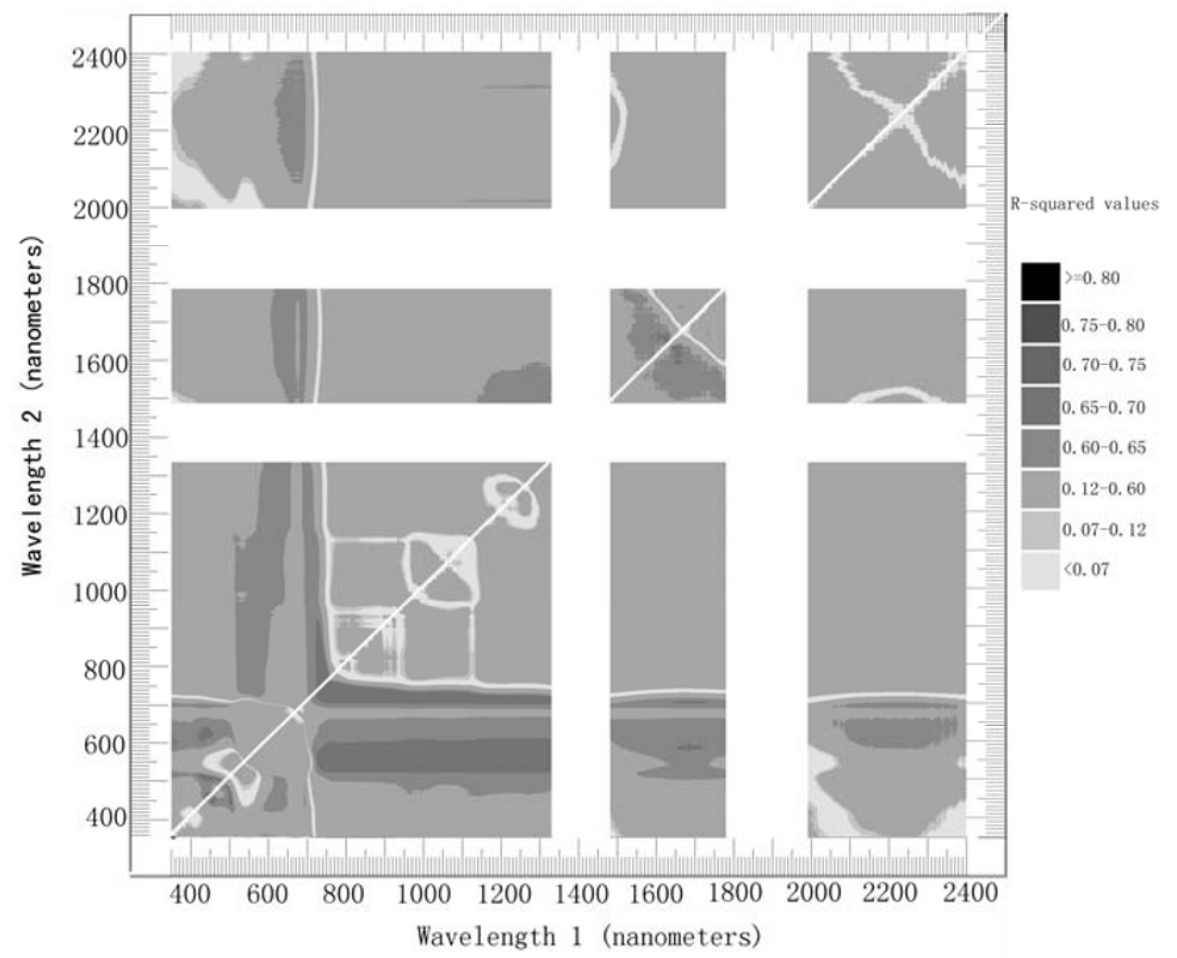

Fig. 1. Contour plot showing the correlation $\left(\mathrm{R}^{2}\right)$ between AGWBM and narrow band RVI values on $31 \mathrm{st}$,August calculated for 1690 narrow bands spread across $\lambda 1(350 \mathrm{~nm}$ to 2500 $\mathrm{nm})$ and $\lambda 2(350 \mathrm{~nm}$ to $2500 \mathrm{~nm})$. 
Table 1. Nine best NBRVIs band centers $(\lambda 1$ and $\lambda 2)$ and band widths $(\Delta \lambda 1$ and $\Delta \lambda 2)$ in $n m$ for the linear NBRVI models for the different rice variables

\begin{tabular}{ccccccccc}
\hline \multicolumn{3}{c}{ Band Centers $(\lambda 1$ and $\lambda 2)$ and Band Widths $((\Delta \lambda 1$ and $\Delta \lambda 2)$ for NBNDVI } \\
\hline \multirow{2}{*}{ date } & \multicolumn{3}{c}{ LAI } & \multicolumn{5}{c}{ LWBM } \\
\cline { 2 - 9 } 23 $3^{\text {th }}$, Ju1. Index 1 & 726 & 27 & 990 & 107 & 730 & 12 & 984 & 60 \\
index 2 & 722 & 26 & 1233 & 191 & 728 & 8 & 1236 & 181 \\
index 3 & 716 & 20 & 1630 & 297 & 720 & 16 & 1629 & 294 \\
index 4 & 708 & 10 & 2189 & 321 & 712 & 7 & 2274 & 29 \\
index 5 & 523 & 14 & 613 & 54 & 523 & 7 & 589 & 34 \\
index 6 & 574 & 111 & 2003 & 24 & 889 & 107 & 731 & 23 \\
index 7 & 901 & 76 & 726 & 13 & 1071 & 63 & 726 & 19 \\
index 8 & 1074 & 5 & 723 & 8 & 755 & 26 & 727 & 14 \\
index 9 & 598 & 46 & 525 & 9 & 591 & 23 & 521 & 6 \\
\hline 30 ${ }^{\text {th }}$ Ju1. Index 1 & 689 & 10 & 1515 & 67 & 698 & 5 & 1190 & 41 \\
index 2 & 617 & 93 & 1515 & 67 & 699 & 9 & 1318 & 18 \\
index 3 & 519 & 27 & 1529 & 96 & 567 & 82 & 1319 & 17 \\
index 4 & 514 & 18 & 2366 & 16 & 580 & 122 & 1630 & 298 \\
index 5 & 593 & 202 & 1629 & 298 & 573 & 23 & 1173 & 12 \\
index 6 & 517 & 13 & 1320 & 17 & 610 & 78 & 2019 & 6 \\
index 7 & 691 & 11 & 979 & 45 & 694 & 12 & 2313 & 37 \\
index 8 & 578 & 123 & 721 & 25 & 605 & 22 & 2312 & 34 \\
index 9 & 721 & 20 & 565 & 88 & 774 & 51 & 547 & 27 \\
\hline
\end{tabular}

\subsection{Frequently occurring optimum bands}

To gain a broad view of the results in this paper, it is useful to consider bands that frequently appear in optimum indices. It can be said that these bands contain an overwhelming fraction of the total rice information in the full spectrum.

The results obtained using narrow band RVI models was used for determining the band centers and widths (Fig 1. Table 1). The procedure of obtaining the band centers and band widths was explained previously. The narrow bands that appear in two-band RVI type models were evaluated. The percentage of these narrow bands in every $50 \mathrm{~nm}$ interval were established (Fig. 2)and their clusters plotted for the $350 \mathrm{~nm}$ to $1330 \mathrm{~nm}, 1480 \mathrm{~nm}$ to $1780 \mathrm{~nm}$, and $1990 \mathrm{~nm}$ to $2400 \mathrm{~nm}$. In NBRVI model type, an overwhelming proportion of crop information was in red-edge $(700 \mathrm{~nm}$ to $750 \mathrm{~nm})$, the intermediate portion of SWIR (1600 nm to $1700 \mathrm{~nm})$, and a portion of green $(500 \mathrm{~nm}$ to $550 \mathrm{~nm})$. These were followed by the moisture-sensitive NIR $(950 \mathrm{~nm}$ to $1000 \mathrm{~nm})$, a particular portion of NIR $(1100 \mathrm{~nm}$ to $1150 \mathrm{~nm})$, and the longer portion of red $(650 \mathrm{~nm}$ to $700 \mathrm{~nm})$. A remarkable about $25 \%$ of all the bands that occur in RVI type model were clustered in $700 \mathrm{~nm}$ to $750 \mathrm{~nm}$ region of the spectrum (Fig. 1, Table 1). 


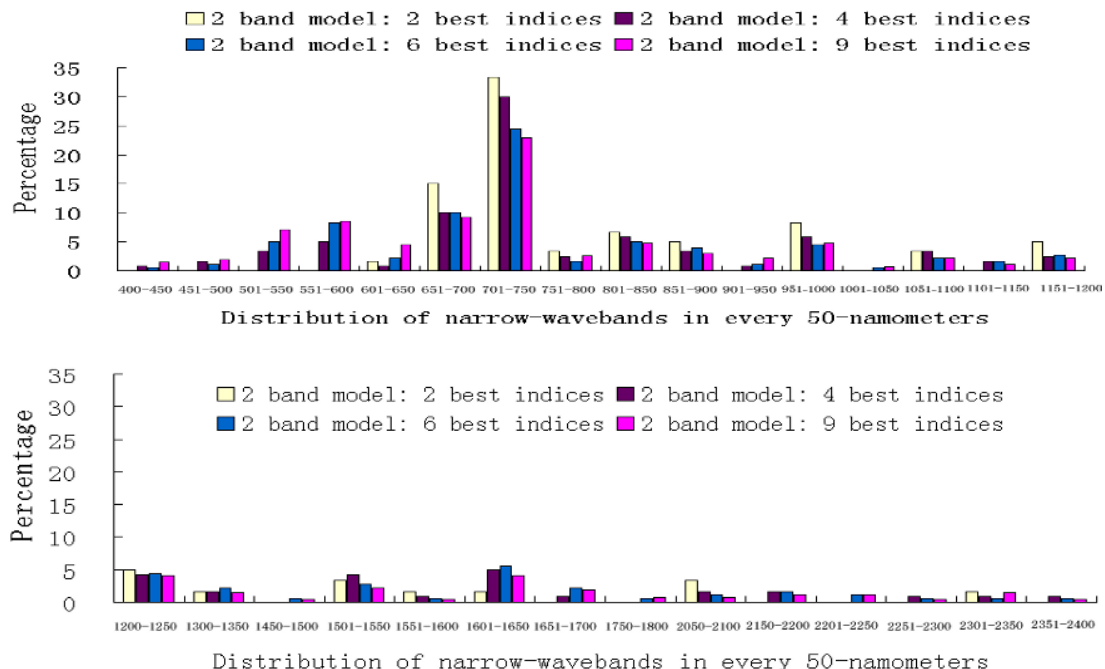

Fig. 2. Percentage of occurrences of hyperspectral narrow bands in the nine best RVI models

The band widths $(\Delta \lambda 1, \Delta \lambda 2)$ were determined from the $\lambda 1$ versus $\lambda 2$ plots such as the ones illustrated in Fig. 1. The $\Delta \lambda 1$ and $\Delta \lambda 2$ of the nine best narrow bands RVI models were used to determine the frequency of occurrence of various band widths as follows:

(1) very narrow bands ( $1 \mathrm{~nm}$ to $15 \mathrm{~nm}$ ), 49 occurrences, $18.1 \%$

(2) narrow bands ( $16 \mathrm{~nm}$ to $30 \mathrm{~nm}$ ), 85 occurrences, $31.5 \%$

(3) intermediate bands (31 nm to $45 \mathrm{~nm}$ ), 25 occurrences, $9.3 \%$

(4) broad bands (greater than $45 \mathrm{~nm}$ ), 111 occurrences, $41.1 \%$

It is clear from these results that nearly $50 \%$ of the bands have narrow (16 $\mathrm{nm}$ to $30 \mathrm{~nm})$ or very narrow band ( $1 \mathrm{~nm}$ to $15 \mathrm{~nm}$ ) widths. If we consider them as a whole, the percentage of them is $49.6 \%$ for RVI. This indicates that narrow bands are very useful to predict rice LAI and LWBM.

The red-edge portion around $720 \mathrm{~nm}$ which represents the maximum band of the first order derivative is the single most frequently occurring band across the variables in NBRVI type of models. This in not surprising since this wavelength has been affected by growth stage and nitrogen levels. The band widths $(\Delta \lambda 1$ or $\Delta \lambda 2)$ for the red-edge narrow bands typically range between $5 \mathrm{~nm}$ to $28 \mathrm{~nm}$. The best suggested band widths for any red-edge narrow band is $15 \mathrm{~nm}$. The other two red narrow bands, $\lambda 4(710 \mathrm{~nm})$ and $\lambda 6(730 \mathrm{~nm})$, are of importance depending on type of rice, growth stage, and growing conditions, including cultural practices, wherein there is a likelihood of red-edge shifting to these bands from the most commonly occurring red-edge band $(720 \mathrm{~nm})$. Indeed red-edge varies significantly depending on host of these variables. 
The $\lambda 2(550 \mathrm{~nm})$ is the green narrow band at the reflectance peak in the visible range. The band $\lambda 1(530 \mathrm{~nm})$ is the point of greatest positive change in slope per unit change in wavelength in visible spectrum, and $\lambda 3(580 \mathrm{~nm})$ is the greatest negative change in slope per unit change in wavelength in visible spectrum for most dates. Similarly, $\lambda 6(720 \mathrm{~nm})$ represents the point of greatest positive change in slope per unit change in wavelength in rededge portion of the spectrum. The $\lambda 5(710 \mathrm{~nm})$ and $\lambda 7(735 \mathrm{~nm})$ are the possible greatest derivative values. The red absorption maximum occurs around $680 \mathrm{~nm}(\lambda 4)$, which is another frequently occurring band. The NIR shoulder can be represented by a broad band or a narrow band centered at $845 \mathrm{~nm}(\lambda 8)$. The $\lambda 9=920 \mathrm{~nm}$ and $\lambda 11=1080 \mathrm{~nm}$ represent the possible peak for maximum reflectance region of the NIR spectrum. Which band the peak reflectance will occur is dependent on a lot of conditions. The $\lambda 10=982 \mathrm{~nm}$ is the center of the moisture-sensitive "trough" portion of NIR, which is strongly related to change in rice moisture and biomass (Penuelas et al., 1993). The size of "trough" in $940 \mathrm{~nm}$ to $1040 \mathrm{~nm}$ region increases with an increase in growth stages and is strongly related to biomass. The $\lambda 12=1125$ $\mathrm{nm}$ represents the sudden decrease after the second possible peak NIR reflectance. The $\lambda 13=1190$ is the second center of the moisture-sensitive "trough" portion of NIR. The $\lambda 14=1630 \mathrm{~nm}$ is the premaxima reflectance of intermediate SWIR. With respect to $\lambda 16=1680 \mathrm{~nm}$, it is the most particular band of high occurrence frequency in the paper. The fifteen bands were selected based on their frequency of occurrence in various models rice variables as discussed throughout this paper. The distribution of the rice information clusters in different waveband portions also shows an overwhelming proportion of quantitative rice information in the band centers of these 15 bands. Many of the optimum bands that were selected make physical sense given what we know about plant chemistry, canopy structure, and plant spectra (Elvidge,1990).

\section{SUMMARY AND CONCLUSIONS}

This research established the optimum number of hyperspectral bands, centers, and widths (Table 1) in the visible, near-infrared and short-wave infrared spectrum for establishing relationships with rice biophysical characteristics. This recommendation is based on the study of eight dates of observation (representing eight growth stages), and wide ranging rice characteristics. A remarkably strong relationship with rice variables is in rededge $(700 \mathrm{~nm}$ to $750 \mathrm{~nm})$, the longer portion of red $(650 \mathrm{~nm}$ to $700 \mathrm{~nm})$, the shorter portion of green $(500 \mathrm{~nm}$ to $550 \mathrm{~nm})$, a particular portion of NIR( $800 \mathrm{~nm}$ to $850 \mathrm{~nm}$ ). They are followed by moisture-sensitive NIR, and two portions of SWIR( $1150 \mathrm{~nm}$ to $1120 \mathrm{~nm}, 1600 \mathrm{~nm}$ to $1650 \mathrm{~nm})$.An 
overwhelming proportion of these channels had band widths that were classified as: (1) very narrow (1 nm to $15 \mathrm{~nm}$ wide) or (2) narrow (16 nm to $30 \mathrm{~nm}$ wide). Most were on the order of $10 \mathrm{~nm}$ to $20 \mathrm{~nm}$ wide (narrow or very narrow). A rigorous procedure adopted here to identify the best narrow band RVI type models showed that the best two-band combinations often involve: (1) a very narrow or a narrow red-edge band and a narrow or a broad NIR band, or (2) a very narrow red-edge band and a narrow or a broad SWIR band, or (3) a broad NIR band and a narrow red band or (4) a narrow green band and a broad NIR and SWIR band.

The study recommends 15 specific narrow bands, centers, and widths, which provide optimal crop information in the whole spectra. These narrow bands include $710 \mathrm{~nm}, 720 \mathrm{~nm}, 735 \mathrm{~nm}, 680 \mathrm{~nm}, 530 \mathrm{~nm}, 550 \mathrm{~nm}, 580 \mathrm{~nm}$, $845 \mathrm{~nm}, 920 \mathrm{~nm}, 982 \mathrm{~nm}, 1080 \mathrm{~nm}, 1125 \mathrm{~nm}, 1190 \mathrm{~nm}, 1630 \mathrm{~nm}$ and 1680 $\mathrm{nm}$. Most of them make physical sense.

\section{ACKNOWLEDGEMENTS}

This work was supported by the National Natural Science Foundation of China (40571115) and the Hi-Tech Research and Development Program (863) of China (2006AA120101)

\section{REFERENCES}

B. Leblon, M. Guerif, F. Baret. The use of remotely sensed data in estimation of PAR use efficiency and biomass production of flooded rice. Remote Sening of Environment, 1991, 38: $147-158$

C. D. Elvidge, and Z. Chen. Comparison of broad-band and narrow-band red and nearinfrared vegetation indices. Remote Sening of Environment, 1995: 54, 38-48

C. D. Elvidge. Visible and near infrared reflectance characteristics of dry plant materials. International Journal of Remote Sensing, 1990, 11(10):1775-1795

C. L. Wiegand, and A. J. Richardson. Use of spectral vegetation indices to infer leaf area, evapotranspiration, and yield: I. Rationale. Agronomy Journal, 1990, 86: 623-629

D. S. Bartlett, M. A. Hardisky, R. W. Johnson, et al.. Continental scale variability in vegetation reflectance and its relationship to canopy morphology. International Journal of Remote Sensing, 1988, 9: 1223-1241

G. A. Blackburn. Quantifying chlorophylls and caroteniods at leaf and canopy scales: An evaluation of some hyperspectral approaches. Remote Sening of Environment, 1998, 66: 273-285

G. A. Carter. Reflectance bands and indices for remote estimation of photosynthesis and stomatal conductance in pine canopies. Remote Sening of Environment, 1998, 63: 61-72

J. P. G. W. Clevers. The application of a weighted infrared-red vegetation index for estimating leaf area index by correcting soil moisture. Remote Sening of Environment, 1989, 29: $25-37$ 
K. S.,Fassnacht S. T. Gower, M. D. MacKenzie,et al. Estimating the leaf area index of north central Wisconsin forests using the Landsat Thematic Mapper. Remote Sening of Environment, 1997, 61: 229-245

M. Shibayama, and T. Akiyama. Estimating grain yield by remote sensing of crop of rice canopies using high spectral resolution reflectance measurements. Remote Sening of Environment, 1991, 36: 45-53

M. Shibayama, W. Takahashi, S. Morinaga, and T. Akiyama. Canopy water deficit detection in paddy rice using high resolution field spectroradiometer. Remote Sening of Environment, 1993, 45: 117-126

N. K. Patel, T. P. Singh, B. Sahai, et al. Spectral response of rice crop and its relation to yield and yield attributes. International Journal of Remote Sensing, 1985, 6: 657-664

P. Gong, R. Pu, J. R. Miller. Coniferous forest leaf area index estimation along the Oregon transact using compact airborne spectrographic imager data. Photogrammetric Engineering and Remote Sensing, 1995, 61: 1107-1117

P. S. Thenkabail, A. D. Ward, and J.G. Lyon. Landsat-5 Thematic Mapper models of soybean and corn crop characteristics. International Journal of Remote Sensing, 1995, 15: 49-61

P. S. Thenkabail, B.S. Ronald, and D.P. Eddy Hyperspectral Vegetation Indices and Their Relationships with Agricultural . Remote Sening of Environment, 1999, 71: 158-182

Q. Y. Tang, and M. G. Feng. DPS@ Data processing system for practical statistics, Chinese Science Press. 2002, 304-311

R. L. Lawrence, W. J. Ripple. Comparisons among vegetation indices and bandwise regression in a highly disturbed, heterogeneous landscape: Mount St. Helens, Washington. Remote Sening of Environment, 1998, 64: 91-102 